\title{
Background substrate and nest semiochemicals mediate ant aggression towards a parasitic beetle
}

\author{
T H O M A S P A R M E N T I E R ${ }^{1,2}$ (D) ${ }^{1}$ Research Unit of Environmental and Evolutionary Biology, Namur Institute \\ of Complex Systems, and Institute of Life, Earth, and the Environment, University of Namur, Namur, Belgium and ${ }^{2}$ Terrestrial \\ Ecology Unit (TEREC), Department of Biology, Ghent University, Ghent, Belgium
}

\begin{abstract}
Background cues may affect the perception and processing of sensory stimuli used by species to detect other organisms. These additional environmental cues change the effectiveness of behavioural responses and eventually influence species interactions. Ants make use of an advanced sensing system to detect intruders, but little is known how cues of the heterogeneous soil substrate influence their behavioural response.

2. Here, the aggressive response of red wood ants towards the beetle Notothecta flavipes, a parasitic nest associate, was tested against a background of two types of nest material present in the heterogeneous nests of wood ants, organic thatch (upper part of the nest) and sand (lower part of the nest). I used plaster as control. In addition, the three types of substrate were conditioned with or without chemical nest recognition cues of the host ant.

3. Ant aggression was strongly affected by the type of background substrate. Compared to a control background of plaster, the likelihood of ant aggression was 2.8 times and 1.7 times lower against a background of organic thatch and sand, respectively. As visual cues were eliminated in the aggression tests, the reduced aggression levels may be caused by the interference of olfactory scents emitted by the substrate. By contrast, an increase of biting attempts was recorded when the background substrate was conditioned with chemical cues of the ants, suggesting that ants defend familiar smelling terrain more fiercely.

4. Overall, these results suggest that the soil background may have complex and spatially variable effects on species interactions in heterogeneous patches.
\end{abstract}

Key words. Ant guest, footprint cues, Formica, masking, myrmecophile, Staphylinidae.

\section{Introduction}

Organisms respond to stimuli that indicate the presence of resources, danger and mates (Bradbury \& Vehrencamp, 2011; O'Connor et al., 2019). However, a suite of other stimuli is present in the environment and may mediate a successful response. These background stimuli may either lower or enhance the detectability of resources or other organisms (Mumm \& Hilker, 2005; Schröder \& Hilker, 2008; O'Connor et al., 2019). An increasing number of studies underpin that anthropogenic

\footnotetext{
Correspondence: Thomas Parmentier, Research Unit of Environmental and Evolutionary Biology, Namur Institute of Complex Systems, and Institute of Life, Earth, and the Environment, University of Namur, Rue de Bruxelles 61, 5000 Namur, Belgium. E-mail: thomas_parmentier@msn.com
}

background stimuli impact the behaviour of animals (Lürling \& Scheffer, 2007; Ward et al., 2008; Dwyer et al., 2013; Delhey \& Peters, 2017). However, background effects are also prevalent in natural systems and are key to different natural processes (Schröder \& Hilker, 2008). Predators, for example, are able to detect their prey more easily when there is a higher contrast between the background substrate and the prey (Clark et al., 2016). Many animals, by contrast, try to reduce the contrast with the background. They blend in with the background by chemically or visually masking the substrate (Akino, 2008; Stevens \& Merilaita, 2011).

Ants are ideal models to test the effect of the background environment on species interactions. They strongly interact with other soil organisms in and on a complex soil background (Lach et al., 2010). A single ant species may build their nest in different types of soil material (Seifert, 2007; Toffin et al., 2010; 
AntWiki, 2020). Conspecific colonies may reside in soil nests, in organic material, in trunks or under rocks scattered across the heterogeneous landscape (Seifert, 2007). In addition, one can find heterogeneity within a single nest when it contains different types of nest material. A good example is a red wood ant nest, which consists of an above-ground part with organic thatch and an extensive subterranean part dug in the inorganic soil (Stockan \& Robinson, 2016). However, within-nest heterogeneity is much more widespread in ants, for example, when the nest houses a waste dump of organic material (Hölldobler \& Wilson, 1990; Wagner et al., 1997; Hart, 2002; Parmentier et al., 2019) or when the nest is partly in a trunk and partly in the soil matrix below (Seifert, 2007; AntWiki, 2020). This implies that substrates different in texture and organic matter content may be present within a single ant nest. Organic soils tend to release high amounts of organic volatiles (Insam \& Seewald, 2010; Ramirez et al., 2010; Peñuelas et al., 2014). Organic volatiles are known to have wide varying effects on the behaviour of insects (Davis et al., 2013; Peñuelas et al., 2014). In some cases, they may hinder the foraging insect to locate its resource when the background volatiles mask the signals released by their prey or host plant (Schröder \& Hilker, 2008). Therefore, it is probable that ant nest material with high organic contents will have a masking effect on intruders and will make it harder for ants to sense them.

The background environment is dynamic and may be altered by species when they leave semiochemicals. A special group of semiochemicals are chemical footprints, which are mostly hydrocarbons that remain in small quantities on the substrate when insects walk (Wüst \& Menzel, 2017). Insect footprints can drive inter-specific interactions, such as short-range host location by parasitoids (Rostás et al., 2008), competition (Goulson et al., 2000; Nakashima et al., 2006) and enemy avoidance (Ninkovic et al., 2013). Footprints also provide valuable information to conspecifics. For example, ladybirds refrain from ovipositing when conspecific chemical tracks are present (Hemptinne et al., 2001). Arguably, the crucial role of footprints has been demonstrated most clearly in the colony communication in social insects (Lenoir et al., 2009). A text book example here is the tarsal scent marking of bumble bees, which allows other foragers of the colony to assess that flowers have been previously visited and depleted of nectar (Goulson et al., 2000).

Ants deposit chemical footprints on the nest walls and the nest surroundings when walking. The composition of these hydrocarbon cues is similar to the blend of nestmate recognition cues they carry on their cuticle (Lenoir et al., 2009). Ant footprints are thought to play a pivotal role in the home range marking of ants (Lenoir et al., 2009; Wüst \& Menzel, 2017). Ants are more aggressive near the nest than in distant and unfamiliar sites (Hölldobler, 1976; Harrison \& Gentry, 1981; Mayade et al., 1993). There is some evidence that high levels of footprints, as especially found in and near the nest, may act as a reliable cue for proximity to the nest and in response ants may enhance their aggression response (Akino \& Yamaoka, 2005; Ozaki et al., 2005; Bos et al., 2011). Territorial defence and ant aggression are often tested towards extranidal enemies, mainly other ants (Hölldobler \& Wilson, 1990; Lach et al., 2010). Yet, many ant species hold a diverse community of parasitic arthropods in and near their nest (Kistner, 1982; Hölldobler \& Wilson, 1990; Kronauer, 2020; Parmentier, 2020). These so-called myrmecophiles can reach high intranidal densities (Parmentier, 2019) and may have a profound effect on the colony's fitness (Hovestadt et al., 2012; Tartally et al., 2019). It is unknown how footprint chemicals interact with different nest substrates and whether they are differently adsorbed. Nevertheless, it can be expected that ants will act more aggressively towards intranidal intruders when familiar home range markings are present.

The aim of this study is to test the effect of the nest background on the interaction between red wood ants and a nest-associated parasitic beetle. The first hypothesis is that the type of nest substrate (thatch, sand soil and plaster) will differently affect the aggression response of the ant towards the beetle. More specifically, it is expected that nest material with high organic contents (thatch), and hence releasing a high amount of organic volatiles, will hinder the detection of intruders the most. The second hypothesis of this study is that ants are likely to be more aggressive in the presence of nest background marked with their home range semiochemicals.

\section{Material and methods}

\section{Study species and sampling}

The rove beetle Notothecta flavipes (Gravenhorst, 1806) (Staphylinidae-Aleocharinae) is a rather unspecialised, obligate ant associate or myrmecophile typically associated with red wood ants (Formica rufa group, host range see appendix S1 in Parmentier et al., 2020), and can reach high intranidal densities (Parmentier, 2019). The beetle was previously found in all sampled red wood ant populations (both in Formica rufa and the narrowly related $F$. polyctena) in North-West Belgium (Parmentier et al., 2015a; Parmentier et al., 2021). The largest local abundance of the beetle in North-West Belgium was hitherto observed in a Formica rufa Linnaeus, 1761 site. Therefore, beetles were collected in two adjacent mounds in this site (Poperinge, $50.886182^{\circ} 2.696505^{\circ}$ ). The beetles were collected by spreading out nest material into a large tray or by placing pitfalls (plaster boxes of which the walls are too slippery for the beetle to climb out, see Parmentier et al., 2021) in and around the nest. Although all life stages of the beetle can be found in the nest, it is often recorded in the surroundings of the nest as well (Parmentier et al., 2021). It is one of the largest rove beetles (body length $3-3.5 \mathrm{~mm}$, Freude et al., 1974) found in the myrmecophile community of red wood ants (body length Formica polyctena 5-9 mm, van Boven, 1977, Fig. 1). The beetle scavenges on prey collected by the ants, ant brood and on dead ant corpses (Parmentier et al., 2016a). Beetles were kept with 50-100 F. rufa workers in a plastic plot (diameter $9.5 \mathrm{~cm}$ ) with a plaster bottom and filled with nest material.

The aggression towards the beetle was tested with Formica polyctena Förster, 1850 which form, in contrast to F. rufa, different large populations in North-West Belgium. Workers were collected in three different sites (FP1: $51.170416^{\circ} 3.156927^{\circ}$, FP2: 51.174867 $3.142057^{\circ}$ and FP3: $51.173466^{\circ} 3.052880^{\circ}$ ) on the sandy soils (Geopunt Vlaanderen, 2020) around Bruges between 


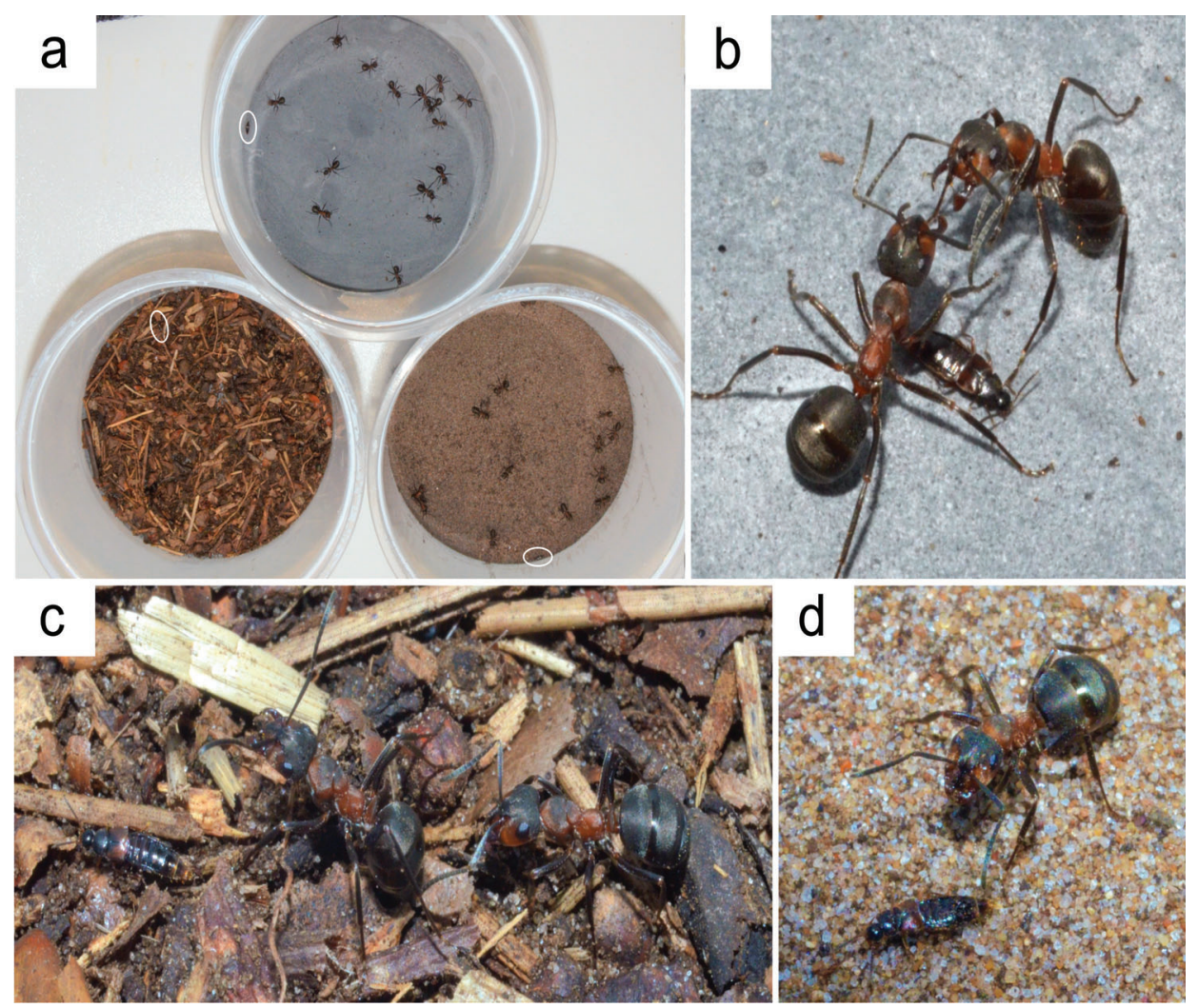

Fig. 1. Overview of the set-up of the aggression tests. (a) Three types of arenas were used: an arena with a plaster substrate (control), with a sandy soil (below-ground part of the nest) and with a substrate with organic thatch (above-ground part of the nest). The aggression tests were conducted with 15 Formica polyctena and one Notothecta flavipes beetle (in white ellipse). The substrate of the arenas was priorly conditioned with semiochemicals or not. Detail of the workers and the beetle on (b) a plaster soil, (c) organic thatch and (d) sandy soil. Note that the aggression tests were conducted under red light (Supporting information Video S1).

the 20 September and 21 October 2020. The nests were located at the edge of deciduous forest patches. The collected nest fragments contained ca. 500 (FP2) or ca. 800 workers (FP1 and FP3). The ants were kept with ca. $2 \mathrm{~L}$ of nest material in plastic boxes. Beetles were collected in a F. rufa nest, but tests were conducted with $F$. polyctena workers. However, it is unlikely that this biased the experiments because of the absence of chemical mimicry in the beetles (beetles found with $F$. polyctena and $F$. rufa have a similar, idiosyncratic profile, see Parmentier et al., 2017), which is also reflected in the inability of red wood ants to discriminate nest-associated beetles from beetles coming from heterospecific nests (additional information 1 in Parmentier et al., 2016b).

Red wood ant nests are characterised by an above-ground mound of organic thatch. However, there is also an extensive underground part of galleries and nest chambers dug out in the soil (Stockan \& Robinson, 2016) of which the volume can exceed that of the above-ground part (pers. observation). Organic thatch was collected from an abandoned (approximately 1 year) F. polyctena nest (Bruges, 51.175026 $3.137902^{\circ}$ ). The thatch contained twigs, leaf fragments and husks from neighbouring deciduous plants. There was also some sand present in the thatch material (Fig. 1c). Sandy soil was collected near the abandoned nest (Fig. 1d).

\section{Experimental set-up}

Aggression of the F. polyctena workers towards the beetle $N$. flavipes was tested in circular arenas (diameter $9.5 \mathrm{~cm}$, height $7 \mathrm{~cm}$ ) (Fig. 1a). The wall of the arenas was coated with fluon to prevent ants and beetles to climb up. The effect of three substrate types, (i) plaster, (ii) sand (below-ground part of the nest) and (iii) organic thatch (above-ground part of the nest), on ant aggression was compared. For the plaster treatment $(\mathrm{P})$, the arena was filled with a $1 \mathrm{~cm}$ layer of plaster mixed with charcoal (7:1 mixture) (Fig. 1b). For the organic thatch treatment $(\mathrm{O})$, $20 \mathrm{ml}$ of the organic material was spread over the plaster bottom (Fig. 1c). For the sand treatment (S), $10 \mathrm{ml}$ of the collected sand was put on a plaster bottom (Fig. 1d). The volumes covered the bottom of the complete arena. Each substrate type was tested with (+) and without (-) semiochemicals previously deposited by the host ant in the lab (full factorial design). Nest material was taken from a long-time abandoned (more than 1 year) red wood ant nest $(\mathrm{O})$ or its surroundings $(\mathrm{S})$. 
In contrast to an active nest where ants constantly deposit semiochemicals (Lenoir et al., 2009; Sprenger \& Menzel, 2020), a long-time abandoned nest is expected to be low or devoid of semiochemicals and can serve as a control. P- did not contain ant semiochemicals as the plaster was freshly poured or rinsed (see below). Substrates conditioned with semiochemicals (+) were prepared by housing 100 workers of one of the three F. polyctena colonies (FP1, FP2 or FP3) on the O (taken from the abandoned mound), S (taken from the surroundings of the abandoned nest) and $\mathrm{P}$ (freshly poured or rinsed) substrates for $48 \mathrm{~h}$. Ants were found permanently on the sand or organic material; they did not dig into these low volumes of substrate. Workers were then gently removed from the arena and later re-united with their colony fragment. The aggression tests were done with $15 \mathrm{~F}$. polyctena workers from the same colony fragment as the ones used for priming the substrate with semiochemicals. The workers could acclimatise to the arena for $10 \mathrm{~min}$. During this acclimatisation, the 15 ants will deposit semiochemicals, but the concentration will be a fraction of that of 100 workers during $48 \mathrm{~h}$. Next, a beetle was introduced, and 20 consecutive interactions (antenna of ant crosses beetle) were scored $10 \mathrm{~s}$ after this introduction. Ant aggression was quantified as the proportion of interactions that were aggressive (biting or opening of the mandibles) out of the 20 interactions (aggressive interactions + non-aggressive interactions, i.e. ignoring and inspecting). Tests had no upper time limit, but were ended after 20 interactions. Tests typically lasted less than 5 min. Beetles were mostly running on all three substrates. They did not hide in the sandy substrate and only occasionally hid under the organic material (Supporting information Video S1). Only interactions with the beetles running and with the body fully exposed (i.e. not partly hidden under the organic material) were considered. For each aggression test, 15 workers were randomly picked from a nest fragment. After a test, the ants were placed back in the colony fragment. Some ants were used for more than one test. As the average number of worker interactions with the beetle in a test were extremely low (20 interactions distributed over 15 workers), it is unlikely that workers re-used in other tests will act differently when confronted again with a $N$. flavipes beetle, for example, due to habituation. Tests were carried out blind with respect to the semiochemical treatment ( + or - ). This blind protocol was achieved by marking the underside of a series of arenas (+ or - ) and randomly shuffling the arenas. After a test, an arena was given a unique number. Following a series of tests, the treatment regime for each test could be determined by linking the number of the corresponding arena with the marking on the underside. The sand and organic material was replaced after each test and whether or not primed again with semiochemicals by 100 workers for $48 \mathrm{~h}$. The plaster bottom of the arenas was re-used but thoroughly cleaned with hexane and $70 \%$ ethanol after each test. A total of 30 different beetles were tested and each beetle was subjected to six tests in a random order, one for each substrate-semiochemical combination $(\mathrm{P}-, \mathrm{P}+, \mathrm{S}-$, $\mathrm{S}+, \mathrm{O}-$ and $\mathrm{O}+$ ). Beetles were not injured and showed similar behaviour across all tests. Workers of colony FP1 and FP3 were each used for the aggression tests of 12 beetles, colony FP2 for those of six beetles. Most interactions between $N$. flavipes and $F$. polyctena will occur inside the nest in darkness. As
Formica polyctena workers cannot detect red light (Roth \& Menzel, 1972), dark conditions were mimicked by conducting the tests under dim red light.

The effect of substrate (P, S, O) and presence of semiochemicals $(+,-)$ on the proportion of aggressive interactions was modelled with a generalised linear mixed model (GLMM, binomial distribution) in $\mathrm{R}$ (version 4.0.0; package lme4, Bates et al., 2015). The ant colony (FP1, FP2 or FP3) used in the aggression test and the interaction between substrate type and the presence of semiochemicals were also incorporated as fixed factors. As each beetle was re-used in six tests, a random intercept "beetle id" was included. Significant over-dispersion (1.8) was detected in this model (tested with the DHARMa R-package, Hartig, 2020). An observation-level random factor, which is a random effect with a unique level for each data point, was therefore added to capture the extra-parametric variation in the data (Browne et al., 2005; Harrison, 2015). Apart from the proportion of aggressive interactions, I focused on the proportion of biting attempts. Biting is the most aggressive behaviour and may, in contrast to opening of the mandibles, lead to injuries. Furthermore, I examined the frequency of abdomen bending in the rove beetle. Many rove beetles bend the abdomen when attacked to emit defensive chemicals (Dettner, 1993) and this defensive behaviour was frequently observed in the beetle $N$. flavipes during interactions with the ants as well (Supporting information Video S1). The tendency to curl the abdomen in $N$. flavipes thus provides hints about the beetle costs, in terms of the production and secretion of repellent volatiles, across the treatment levels. GLMM models with the same predictors and random factors as described above for the aggression model were run to explain the proportion of biting attempts and the likelihood of abdomen curling by the beetle during an interaction. The residuals of the model with abdomen curling also showed over-dispersion and consequently an observation-level random factor was here included as well. Significance of the parameters of the three models was tested using type-III likelihood ratio tests implemented in the "mixed" function of the R-package afex (Singmann et al., 2020). All means presented with results are estimated marginal means (emmeans package) (Lenth, 2020). Post hoc contrasts were tested with the emmeans function in the emmeans package (Lenth, 2020).

\section{Results}

The proportion of aggressive interactions (biting or opening of the mandibles) of the red wood ant $F$. polyctena was highly dependent on the background substrate (binomial GLMM, LRT-test, df $=2, \chi^{2}=108.48, P<0.001$, Fig. 2). The beetles elicited the lowest level of aggressive interactions on organic thatch substrate (proportion aggressive interactions $=0.18,95 \%$ $\mathrm{CI}=0.16-0.22$, Fig. 2), an intermediate level on sand (proportion aggressive interactions $=0.30,95 \% \mathrm{CI}=0.26-0.34$, Fig. 2), and the highest degree on plaster (proportion aggressive interactions $=0.52,95 \% \mathrm{CI}=0.47-0.56$, Fig. 2). Pairwise contrasts of the level of aggression between all substrate types (plaster vs. sand, plaster vs. organic and sand vs. organic) were all highly significant $(P<0.001$ for all three post hoc Tukey 

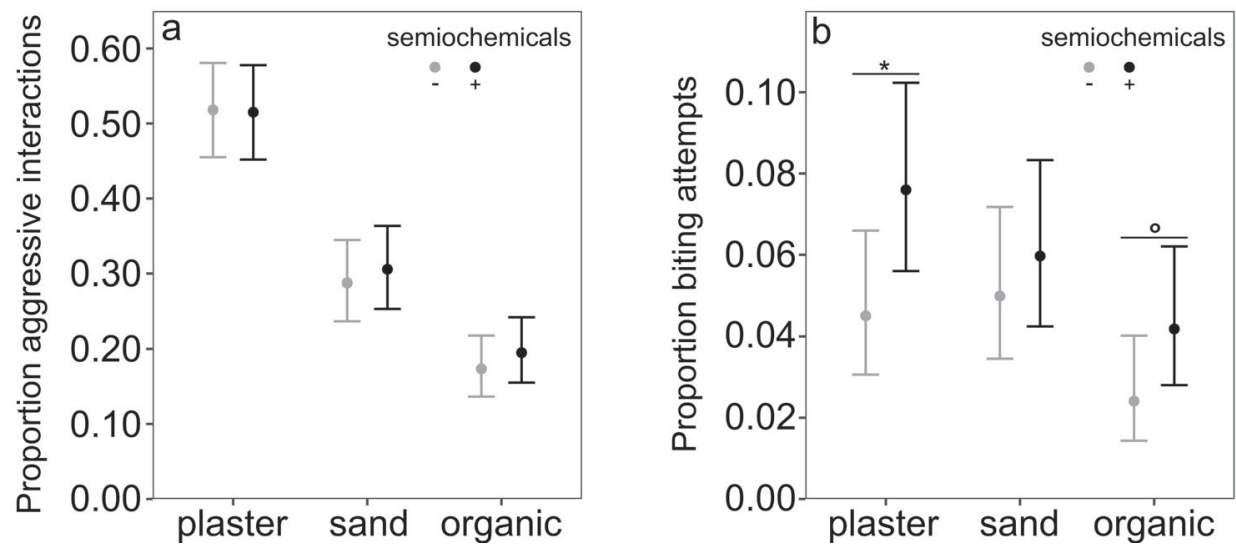

Fig. 2. Effect of substrate and semiochemicals on (a) the proportion of aggressive interactions (biting attempts or opening mandibles) and on (b) biting attempts. Error bars represent $95 \%$ confidence intervals. The effect of semiochemicals was compared per substrate type (post hoc contrasts: $* P<0.05$, ${ }^{\circ} P<0.10$, not indicated $P>0.10$ ).

contrasts, Fig. 2). The presence of semiochemicals on the substrate did not affect the proportion of aggressive interactions of the ant towards the beetle (binomial GLMM, LRT-test, $\mathrm{df}=1$, $\chi^{2}=0.48, P=0.49$, Fig. 2). There was no interaction effect between the presence of semiochemicals and substrate type, i.e. for all three substrates, no effect of semiochemicals was found on the proportion of aggressive interactions of the ants (interaction substrate $\times$ semiochemicals, binomial GLMM, LRT-test, df $=2, \chi^{2}=0.38, P=0.83$, Fig. 2). Ant colonies differed in the likelihood to engage in an aggressive interaction (binomial GLMM, LRT-test, $\mathrm{df}=2, \chi^{2}=10.11, P=0.006$ ), with colony FP2 displaying a significant lower proportion of aggressive interactions than the other two colonies.

In a second part, I only focused on biting, which is the most aggressive behaviour. The propensity to bite the beetle was, in line with the model explaining the proportion of aggressive interactions, dependent on the substrate (binomial GLMM, LRT-test, df $=2, \chi^{2}=11.69, P=0.003$, Fig. 2). Ants tried to bite the beetle less frequently on organic soil (proportion biting attempts $=0.03,95 \% \mathrm{CI}=0.02-0.04$, Fig. 2), than on sand (proportion biting attempts $=0.05,95 \% \mathrm{CI}=0.05-0.07$, pairwise Tukey contrast organic vs. sand: $P=0.006$, Fig. 2), and plaster (proportion biting attempts $=0.06,95 \% \mathrm{CI}=0.05-0.08$, pairwise Tukey contrast organic vs. plaster: $P=0.002$, Fig. 2). No difference in biting attempts was found in tests on sand and plaster (pairwise Tukey contrast sand vs. plaster: $P=0.67$, Fig. 2). The proportion of biting attempts was higher when ants could deposit semiochemicals on the substrate prior to the tests (binomial GLMM, LRT-test, $\mathrm{df}=1, \chi^{2}=7.60$, $P=0.006$, Fig. 2). A significant increase in the proportion of biting attempts was particularly found on a plaster substrate with semiochemicals compared to a plaster substrate without semiochemicals (Post hoc pairwise contrasts, $P=0.024$, Fig. 2 ). Ants showed a higher tendency to bite on organic material and sand when it was primed with their semiochemicals, but these results did not reach significance (organic thatch: $P=0.082$, sand: $P=0.45$, Fig. 2 ). Colonies did not differ in their propensity to bite (binomial GLMM, LRT-test, $\mathrm{df}=2, \chi^{2}=0.15, P=0.93$ ), and there was also no significant interaction effect (i.e. the positive effect of semiochemicals on biting attempts was similar across all soil types) between soil substrate and the presence of semiochemicals (binomial GLMM, LRT-test, $\mathrm{df}=2, \chi^{2}=1.35$, $P=0.51$, Fig. 2). The beetle mostly succeeded to slip through the mandibles of the ant. However, ants were able to grab and pick up the beetle five times on plaster, five times on the sand soil, but never on the organic soil.

The beetle Notothecta flavipes mostly avoided agonistic interactions by running away. Regularly, it also curled its abdomen when attacked, which is likely to emit defensive chemicals. The beetle curled its abdomen less frequently in an arena with organic material (proportion $=0.10,95 \% \mathrm{CI}=0.07-0.13$ ) than with sand (proportion $=0.12,95 \% \mathrm{CI}=0.09-0.15$ ) and plaster (proportion $=0.12,95 \% \mathrm{CI}=0.09-0.16$ ), but no significance was reached for the predictor soil (binomial GLMM, LRT-test, $\mathrm{df}=2, \chi^{2}=3.54, P=0.17$ ).

The dataset and R-code to undertake the analyses can be found in supplementary materials Appendices S2 and S3.

\section{Discussion}

This study shows for the first time that the type of substrate and semiochemicals deposited on the substrate mediate the aggression response of ants towards intranidal associates. The results are in line with a large body of literature, which demonstrated that the aggression response of ants is complex and context-dependent. Multiple factors affect aggression in ants, such as the proximity of nestmates (Tanner, 2006; Sagata \& Lester, 2009), worker size (Nowbahari et al., 1999; Parmentier et al., 2015b), worker age (Nowbahari \& Lenoir, 1989), habituation (Langen et al., 2000), nest proximity (Hölldobler, 1976; Harrison \& Gentry, 1981; Mayade et al., 1993) and the presence of semiochemicals (Mayade et al., 1993). The results here underline that the soil background is a hitherto unaccounted extrinsic factor that is involved in the complex aggression response of ants as well.

Red wood ant nests construct heterogeneous nests with an above-ground mound of organic thatch and a below-ground soil 
part (Stockan \& Robinson, 2016). The proportion of aggressive interactions of red wood ants towards the parasitic beetle associate Notothecta flavipes was 1.6 times higher on sandy soil than on organic thatch. The experienced level of aggression within a single nest can thus be different according to the type of background substrate. Many ant nests are composed of different types of material. There are also ants that construct homogeneous nests, but which are not choosy about the type of nest building material. Then, one ant species can reside in nests composed of different material in the same patch (Seifert, 2007; AntWiki, 2020). The within and among variation in nest substrate can result in spatially variable levels of aggression experienced by the associates, which in turn could affect the distribution of the associates in and among nests. Guests of social insects prefer different niches in the nest (von Beeren et al., 2010; Parmentier et al., 2016b). Probably, these preferences can partly be driven by the background material of the niches. The distribution of some associates may be constrained to locations in the nest or in nests with a substrate that dims the aggression response. This effect of the soil substrate on spatial preferences may have a stabilizing effect on the populations of multiple co-habiting symbiont species. The covariance between symbiont species frequencies across substrate types may lead to weaker overall interactions in the symbiont community. This effect can contribute to "growth-density covariance" (Barabás et al., 2018), a mechanism that may ultimately promote the coexistence of multiple symbionts.

It should be noted that other factors could lead to variable levels of aggression within a nest. Most importantly, ant density is not uniformly distributed across the nest (Hölldobler \& Wilson, 1990). Some niches, such as the brood chambers, house large densities of workers and are consequently harder to colonise for parasites. In addition, the tests here were conducted on the substrate in a $2 \mathrm{D}$ setting, yet the nest is a $3 \mathrm{D}$ environment with many hiding places. Hiding is likely to be easier in organic material such as thatch than in sandy material. Consequently, the number of effective interactions between ant and parasite will be lower in thatch. Thatch thus appears to be an ideal environment for ant-associated arthropods, because of the high hiding potential and the lower aggression against this background when an interaction takes place.

The proportion of aggressive interactions was much higher on plaster than on a natural substrate, being 2.8 and 1.7 times more likely on plaster than on organic thatch and sand, respectively. Much of our insights into the aggression response of ants, either towards other ants or parasitic arthropods, are derived from lab colonies and subsequent tests with an artificial substrate such as plaster or plastic (e.g. Roulston et al., 2003; Kabashima et al., 2007; Sagata \& Lester, 2009; Von Beeren et al., 2010; Parmentier et al., 2015b). An artificial substrate might be more stressful than a natural substrate, which could translate into higher aggression. However, red wood ants do not show apparent signs of stress on a plaster substrate. Previous studies already hinted that accounting the natural nest substrate may be essential to understand aggression responses in ants (Crosland, 1989; Heinze et al., 1996). Ants may incorporate cues of the nest environment in the colony odour, leading to lower levels of aggression towards conspecific colonies that house in the same type of nest material (Heinze et al., 1996). Nest material may, as hinted by this study, affect the aggressive behaviour in ants in another way, this is by impairing the detection of an intruder.

The lower levels of aggression displayed on sand and especially on organic material may be driven by different processes that are difficult to tease apart. Ants rely heavily on the use of scents to forage (Czaczkes et al., 2015), to communicate (Billen \& Morgan, 1998) but also to discriminate intruders from nestmates (Akino et al., 2004; van Zweden \& d'Ettorre, 2010). Chemical sense is likely the most important tool to detect enemies inside the dark nest. This crucial role of chemical senses inside the nest is maybe best demonstrated with intranidal parasites that exploit the chemical detection system by mimicking the cuticular recognition cues (Vander Meer \& Wojcik, 1982; van Zweden \& d'Ettorre, 2010). They reside unnoticed inside the nest because ants cannot discriminate nestmates from similar smelling organisms. The impact of background odours on resource location in insects have been well documented, particularly in insect herbivores and parasitoids (Schröder \& Hilker, 2008; Wilson et al., 2015). Odours can enhance the detectability of a target (Mumm \& Hilker, 2005), but more commonly have a masking effect (Mauchline et al., 2005; Schröder \& Hilker, 2008; Wilson et al., 2015). The rove beetle in this study does not show mimicry and is easily detected on a plaster background (Parmentier et al., 2017), but much harder on sand and organic material. Organic material, particularly, is a rich source of volatile organic compounds, which are formed during decomposition by microorganisms such as bacteria and fungi (Davis et al., 2013; Peñuelas et al., 2014). It is probable that organic volatiles released by the sand and thatch material interfere with the beetle odour and make it less detectable. Alternatively, soil volatiles may affect the behaviour of soil insects and induce avoidance (Davis et al., 2013). It is thus possible that organic substrates change the behaviour of the ants (e.g. alertness), resulting in lower levels of aggression. In addition, the ants and the beetle may behave differently according to the texture of the substrate. There is evidence that ants move faster on a fine than on a coarse substrate (Nielsen, 2001; Bernadou \& Fourcassié, 2008). By analogy, one would expect that the ants would move faster on the smooth plaster. This would result in a shorter interaction time with the beetles on plaster and, in contrast with the reported results, one would then expect a smaller likelihood of an aggression response of an ant when encountering the beetle.

Red wood ants attempted to bite the beetle more frequently when the background material was marked with their footprint semiochemicals. An elevated aggression response in the presence of footprint semiochemicals has been demonstrated in experiments with ant competitors (Akino \& Yamaoka, 2005; Ozaki et al., 2005; Bos et al., 2011). The results here show a similar stimulating effect of semiochemicals on the attempts to bite an unrelated parasite living in the nest. Opening of the mandibles, a weaker aggression response, was not affected by the presence of semiochemicals. Generally, the location in which an agonistic interaction takes place can have a profound effect on the level of aggression displayed (Baker, 1983; Reeve, 1989). In ants, aggression appears to increase closer to the nest (Hölldobler, 1976; Mayade et al., 1993; Starks et al., 1998; Knaden 
\& Wehner, 2003). The nest is the most valuable resource of ant colonies as it contains the developing brood, reproductive individuals, food stores and offers a homeostatic environment (Hölldobler \& Wilson, 1990). The elevated aggression on and near the nest is in line with the acceptance threshold theory that predicts that aggression should increase with the value of the resource being defended (Reeve, 1989). Densities of nestmates are also highest in and near the nest, which allows the sharing of the costs of aggression among workers (Buczkowski \& Silverman, 2005) and the overwhelming of large intruders (Stapley, 1998). Footprint concentrations can be a reliable cue for wood ants to assess their distance from the nest and to inform about the density of nestmates as footprints levels are highest near, and in the nest (Devigne \& Detrain, 2006; Lenoir et al., 2009). These cues may trigger them to adaptively tune their aggression response towards intruders near and in the nest. This hypothesis could be further supported when it is shown that encounters with beetles outside the nest are less aggressive than those occurring in the nest. The effect of semiochemicals on biting attempts was not observed on a sand substrate, which might be related to lower adsorption of the footprints on this substrate (Cheng \& Huang, 2004).

The present work underpins that the soil context plays an important role in the aggressive encounters between ants and their enemies. Significantly lower aggression levels were reported on natural substrates compared with an artificial substrate. Researchers should be aware of the effect of a natural soil background on ant behaviour. Hence, the use of a natural substrate in behavioural tests should be promoted to assess ant behaviour and the impact on its enemies more realistically.

\section{Acknowledgements}

I thank Agentschap Natuur en Bos (ANB) and domeinen West-Vlaanderen for granting permission to sample the specimens required for this study. I am very grateful for the insightful comments and suggestions of Frederik De Laender, Dries Bonte and two anonymous reviewers on an earlier version of this manuscript. This study was funded by the Fonds Wetenschappelijk Onderzoek-FWO (Junior postdoctoral fellowship 1203020 N) and the Fonds de la Recherche Scientifique-FNRS (Chargé de recherches 30257865).

The author declares that there is no conflict of interest.

\section{Ethics Statement}

The Agency of Nature and Forest (ANB) granted permission to the sampling of red wood ant workers and myrmecophiles needed for this study (reference number ANB/BL-FF/V20-00131).

\section{Data availability statement}

The data and code that support the findings of this study are included as supplementary material.

\section{Supporting Information}

Additional supporting information may be found online in the Supporting Information section at the end of the article.

Video S1. Interactions between Formica polyctena and Notothecta flavipes against the three tested background substrates.

Appendix S2. Dataset.

Appendix S3. R-code to undertake the analyses.

\section{References}

Akino, T. (2008) Chemical strategies to deal with ants : a review of mimicry, camouflage, propaganda, and phytomimesis by ants (Hymenoptera: Formicidae) and other arthropods. Myrmecological News, 11, 173-181.

Akino, T. \& Yamaoka, R. (2005) Trail discrimination signal of Lasius japonicus (Hymenoptera: Formicidae). Chemoecology, 15, 21-30. https://doi.org/10.1007/s00049-005-0288-6.

Akino, T., Yamamura, K., Wakamura, S. \& Yamaoka, R. (2004) Direct behavioral evidence for hydrocarbons as nestmate recognition cues in Formica japonica (Hymenoptera: Formicidae). Applied Entomology and Zoology, 39, 381-387. https://doi.org/10.1303/aez.2004.381.

AntWiki. (2020) AntWiki. http://www.antwiki.org/wiki/Welcome_to_ AntWiki. Accessed 17 Nov 2020.

Baker, R.R. (1983) Insect territoriality. Annual Review of Entomology, 28, 65-89. https://doi.org/10.1139/z83-064.

Barabás, G., D’Andrea, R. \& Stump, S.M. (2018) Chesson's coexistence theory. Ecological Monographs, 88, 277-303. https://doi.org/10 .1002/ecm.1302.

Bates, D.M., Maechler, M., Bolker, B. \& Walker, S. (2015) Fitting linear mixed-effects models using lme4. Journal of Statistical Software, 67, 1-48.

von Beeren, C., Maruyama, M., Hashim, R. \& Witte, V. (2010) Differential host defense against multiple parasites in ants. Evolutionary Ecology, 25, 259-276. https://doi.org/10.1007/s10682-010-9420-3.

Bernadou, A. \& Fourcassié, V. (2008) Does substrate coarseness matter for foraging ants? An experiment with Lasius Niger (Hymenoptera; Formicidae). Journal of Insect Physiology, 54, 534-542. https://doi .org/10.1016/j.jinsphys.2007.12.001.

Billen, J. \& Morgan, E.D. (1998) Pheromone communication in social insects: Sources and secretions. Pheromone Communication in Social Insects Ants, Wasps, Bees, and Termites (ed. by R. K. Vander Meer, M. D. Breed, K. E. Espelie and M. L. Winston), pp. 3-33. Oxford, Westview Press, Boulder.

Bos, N., Grinsted, L. \& Holman, L. (2011) Wax on, wax off : nest soil facilitates indirect transfer of recognition cues between ant nestmates. PLoS One, 6, 2-7. https://doi.org/10.1371/journal.pone.0019435.

van Boven, J.K.A. (1977) De mierenfauna van België. Acta Zoologica et Pathologica Antverpiensia, 67, 1-191.

Bradbury, J.W. \& Vehrencamp, S.L. (2011) Principles of Animal Communication, 2nd edn. Sinauer Associates, Sunderland, MA.

Browne, W.J., Subramanian, S.V., Jones, K. \& Goldstein, H. (2005) Variance partitioning in multilevel logistics models with over-dispersion. Journal of the Royal Statistical Society. Series A, 168, 599-613.

Buczkowski, G. \& Silverman, J. (2005) Context-dependent nestmate discrimination and the effect of action thresholds on exogenous cue recognition in the Argentine ant. Animal Behaviour, 69, 741-749. https://doi.org/10.1016/j.anbehav.2004.06.027. 
Cheng, A.L. \& Huang, W.L. (2004) Selective adsorption of hydrocarbon gases on clays and organic matter. Organic Geochemistry, 35, 413-423. https://doi.org/10.1016/j.orggeochem.2004.01.007.

Clark, D.L., Kizer Zeeff, C., Karson, A., Roberts, J.A. \& Uetz, G.W. (2016) Risky courtship: background contrast, ornamentation, and display behavior of wolf spiders affect visual detection by toad predators. Ethology, 122, 364-375. https://doi.org/10.1111/eth.12476.

Crosland, M.W.J. (1989) Kin recognition in the ant Rhytidoponera confusa I. Environmental odour. Animal Behaviour, 37, 912-919. https://doi.org/10.1016/0003-3472(89)90135-8.

Czaczkes, T.J., Grüter, C. \& Ratnieks, F.L.W. (2015) Trail pheromones: an integrative view of their role in social insect colony organization. Annual Review of Entomology, 60, 581-599. https://doi.org/10.1146/ annurev-ento-010814-020627.

Davis, T.S., Crippen, T.L., Hofstetter, R.W. \& Tomberlin, J.K. (2013) Microbial volatile emissions as insect semiochemicals. Journal of Chemical Ecology, 39, 840-859. https://doi.org/10.1007/s10886013-0306-z.

Delhey, K. \& Peters, A. (2017) Conservation implications of anthropogenic impacts on visual communication and camouflage. Conservation Biology, 31, 30-39. https://doi.org/10.1111/cobi.12834.

Dettner, K. (1993) Defensive secretions and exocrine glands in free-living staphylinid beetles-their bearing on phylogeny (Coleoptera: Staphylinidae). Biochemical Systematics and Ecology, 21, 143-162.

Devigne, C. \& Detrain, C. (2006) How does food distance influence foraging in the ant Lasius Niger: the importance of home-range marking. Insectes Sociaux, 53, 46-55. https://doi.org/10.1007/s00040005-0834-9.

Dwyer, R.G., Bearhop, S., Campbell, H.A. \& Bryant, D.M. (2013) Shedding light on light: benefits of anthropogenic illumination to a nocturnally foraging shorebird. The Journal of Animal Ecology, 82, 478-485. https://doi.org/10.1111/1365-2656.12012.

Freude, H., Harde, K.W. \& Lohse, G.A. (1974) Käfer Mitteleuropas. Bd 5. Staphylinidae II (Hypocyphtinae und Aleocharinae), Pselaphidae. Goecke et Evers Verlag, Krefeld.

Geopunt Vlaanderen. (2020) Bodemkaart. https://www.geopunt.be/ kaart. Accessed 17 Nov 2020.

Goulson, D., Stout, J.C., Langley, J. \& Hughes, W.O.H. (2000) Identity and function of scent marks deposited by foraging bumblebees. Journal of Chemical Ecology, 26, 2897-2911. https://doi.org/10 .1023/A:1026406330348.

Harrison, X.A. (2015) A comparison of observation-level randomeffect and Beta-binomial models for modelling overdispersion in binomial data in ecology \& evolution. PeerJ, 2015, e1114. https://doi.org/10 $.7717 /$ peerj. 1114

Harrison, J.S. \& Gentry, J.B. (1981) Foraging pattern, colony distribution, and foraging range of the Florida harvester ant, Pogonomyrmex badius. Ecology, 62, 1467-1473.

Hart, A.G. (2002) Waste management in the leaf-cutting ant Atta colombica. Behavioral Ecology, 13, 224-231. https://doi.org/10.1093/ beheco/13.2.224.

Hartig, F. (2020) DHARMa: Residual Diagnostics for Hierarchical (Multi-level/Mixed) Regression Models. R Package Version 0.3.3.0. https://CRAN.R-project.org/package=DHARMa.

Heinze, J., Foitzik, S., Hippert, A. \& Hölldobler, B. (1996) Apparent dear-enemy phenomenon and environment-based recognition cues in the ant Leptothorax nylanderi. Ethology, 102, 510-522. https://doi .org/10.1111/j.1439-0310.1996.tb01143.x.

Hemptinne, J.L., Lognay, G., Doumbia, M. \& Dixon, A.F.G. (2001) Chemical nature and persistence of the oviposition deterring pheromone in the tracks of the larvae of the two spot ladybird, Adalia bipunctata (Coleoptera: Coccinellidae). Chemoecology, 11, 43-47. https://doi.org/10.1007/PL00001831.
Hölldobler, B. (1976) Recruitment behavior, home range orientation and territoriality in harvester ants, Pogonomyrmex. Behavioral Ecology and Sociobiology, 1, 3-44. https://doi.org/10.1007/BF00299951.

Hölldobler, B. \& Wilson, E.O. (1990) The Ants. Cambridge, MA: Harvard University Press, Cambridge, Massachusetts.

Hovestadt, T., Thomas, J.A., Mitesser, O. \& Elmes, G.W. (2012) Unexpected benefit of a social parasite for a key fitness component of its ant host. The American Naturalist, 179, 110-123. https://doi .org/10.1086/663203.

Insam, H. \& Seewald, M.S.A. (2010) Volatile organic compounds (VOCs) in soils. Biology and Fertility of Soils, 46, 199-213. https:// doi.org/10.1007/s00374-010-0442-3.

Kabashima, J.N., Greenberg, L., Rust, M.K. \& Paine, T.D. (2007) Aggressive interactions between Solenopsis invicta and Linepithema humile (Hymenoptera: Formicidae) under laboratory conditions. Journal of Economic Entomology, 100, 148-154. https://doi.org/10 .1603/0022-0493(2007)100[148:AIBSIA]2.0.CO;2.

Kistner, D.H. (1982) The social insects' bestiary. Social Insects, Vol. 3 (ed. by H. R. Hermann), pp. 1-244. Academic Press, London.

Knaden, M. \& Wehner, R. (2003) Nest defense and conspecic enemy recognition in the desert ant. Journal of Insect Behavior, 16, $717-730$

Kronauer, D.J.C. (2020) Army Ants: Nature's Ultimate Social Hunters. Harvard University Press, Cambridge, MA.

Lach, L., Parr, C.L. \& Abbott, K.L. (2010) Ant Ecology. Oxford University press, Oxford

Langen, T.A., Tripet, F. \& Nonacs, P. (2000) The red and the black: habituation and the dear-enemy phenomenon in two desert Pheidole ants. Behavioral Ecology and Sociobiology, 48, 285-292. https://doi .org/10.1007/s002650000223.

Lenoir, A., Depickère, S., Devers, S., Christidès, J.-P. \& Detrain, C. (2009) Hydrocarbons in the ant Lasius Niger: from the cuticle to the nest and home range marking. Journal of Chemical Ecology, 35, 913-921. https://doi.org/10.1007/s10886-009-9669-6.

Lenth, R. (2020) Emmeans: Estimated Marginal Means, Aka Least-Squares Means. R Package Version 12-1. https://CRAN R-project.org/package=emmeans.

Lürling, M. \& Scheffer, M. (2007) Info-disruption: pollution and the transfer of chemical information between organisms. Trends in Ecology \& Evolution, 22, 374-379. https://doi.org/10.1016/j.tree 2007.04.002.

Mauchline, A.L., Osborne, J.L., Martin, A.P., Poppy, G.M. \& Powell, W. (2005) The effects of non-host plant essential oil volatiles on the behaviour of the pollen beetle Meligethes aeneus. Entomologia Experimentalis et Applicata, 114, 181-188. https://doi.org/10.1111/j $.1570-7458.2005 .00237 . x$.

Mayade, S., Cammaerts, M.C. \& Suzzoni, J.P. (1993) Home-range marking and territorial marking in Cataglyphis cursor (Hymenoptera, Formicidae). Behavioural Processes, 30, 131-142. https://doi.org/10 .1016/0376-6357(93)90003-A.

Mumm, R. \& Hilker, M. (2005) The significance of background odour for an egg parasitoid to detect plants with host eggs. Chemical Senses, 30, 337-343. https://doi.org/10.1093/chemse/bji028.

Nakashima, Y., Birkett, M.A., Pye, B.J. \& Powell, W. (2006) Chemically mediated intraguild predator avoidance by aphid parasitoids: interspecific variability in sensitivity to semiochemical trails of ladybird predators. Journal of Chemical Ecology, 32, 1989-1998. https:// doi.org/10.1007/s10886-006-9123-y.

Nielsen, M.G. (2001) Energetic cost of foraging in the ant Rhytidoponera aurata in tropical Australia. Physiological Entomology, 26, 248-253. https://doi.org/10.1046/j.0307-6962.2001.00242.x.

Ninkovic, V., Feng, Y., Olsson, U. \& Pettersson, J. (2013) Ladybird footprints induce aphid avoidance behavior. Biological Control, 65, 63-71. https://doi.org/10.1016/j.biocontrol.2012.07.003. 
Nowbahari, E. \& Lenoir, A. (1989) Age-related changes in aggression in ant Cataglyphis cursor (Hymenoptera, Formicidae): influences on intercolonial relationships. Behavioural Processes, 18, 173-181.

Nowbahari, E., Fénéron, R. \& Malherbe, M. (1999) Effect of body size on aggression in the ant, Cataglyphis Niger (Hymenoptera ; Formicidae). Aggressive Behavior, 25, 369-379.

O’Connor, M.I., Pennell, M.W., Altermatt, F., Matthews, B., Melián, C.J. \& Gonzalez, A. (2019) Principles of ecology revisited: integrating information and ecological theories for a more unified science. Frontiers in Ecology and Evolution, 7, 1-20. https://doi .org/10.3389/fevo.2019.00219.

Ozaki, M., Satoji, Y. \& Yamaoka, R. (2005) Aggressive behavior influenced by the footprint hydrocarbons in the ant, Camponotus japonicus. Zoological Science, 22, 1475.

Parmentier, T. (2019) A dazzling number of beetles (Coleoptera) in a hibernating nest of red wood ants, Formica rufa Linnaeus (Hymenoptera: Formicidae). The Coleopterists Bulletin, 73, 1-4. https://doi.org/10.1649/0010-065X-73.3.761.

Parmentier, T. (2020) Guests of social insects. Encyclopedia of Social Insects (ed. by C. Starr). Springer, Cham. https://doi.org/10.1007/ 978-3-319-90306-4_164-1.

Parmentier, T., Dekoninck, W. \& Wenseleers, T. (2015a) Metapopulation processes affecting diversity and distribution of myrmecophiles associated with red wood ants. Basic and Applied Ecology, 16, 553-562. https://doi.org/10.1016/j.baae.2015.04.008.

Parmentier, T., Dekoninck, W. \& Wenseleers, T. (2015b) Context-dependent specialization in colony defence in the red wood ant Formica rufa. Animal Behaviour, 103, 103-167. https:// doi.org/10.1016/j.anbehav.2015.02.023.

Parmentier, T., Bouillon, S., Dekoninck, W. \& Wenseleers, T. (2016a) Trophic interactions in an ant nest microcosm: a combined experimental and stable isotope $(\delta 13 \mathrm{C} / \delta 15 \mathrm{~N})$ approach. Oikos, 125, 1182-1192. https://doi.org/10.1111/oik.02991.

Parmentier, T., Dekoninck, W. \& Wenseleers, T. (2016b) Do well-integrated species of an inquiline community have a lower brood predation tendency? A test using red wood ant myrmecophiles. BMC Evolutionary Biology, 16, 12. https://doi.org/10.1186/s12862016-0583-6.

Parmentier, T., Dekoninck, W. \& Wenseleers, T. (2017) Arthropods associate with their red wood ant host without matching nestmate recognition cues. Journal of Chemical Ecology, 43, 43-661. https:// doi.org/10.1007/s10886-017-0868-2.

Parmentier, T., Gaju-Ricart, M., Wenseleers, T. \& Molero-Baltanás, R. (2019) Strategies of the beetle Oochrotus unicolor (Tenebrionidae) thriving in the waste dumps of seed-harvesting Messor ants (Formicidae). Ecological Entomology, 4, 1-11. https://doi.org/10.1111/een .12832 .

Parmentier, T., De Laender, F. \& Bonte, D. (2020) The topology and drivers of ant-symbiont networks across Europe. Biological Reviews, 95, 1664-1688. https://doi.org/10.1111/brv.12634.

Parmentier, T., Claus, R., De Laender, F. \& Bonte (2021) Moving apart together: co-movement of a symbiont community and their ant host, and its importance for community assembly. Movement Ecology, 9, 25. https://doi.org/10.1186/s40462-021-00259-5.

Peñuelas, J., Asensio, D., Tholl, D. et al. (2014) Biogenic volatile emissions from the soil. Plant, Cell and Environment, 37, 1866-1891. https://doi.org/10.1111/pce.12340.

Ramirez, K.S., Lauber, C.L. \& Fierer, N. (2010) Microbial consumption and production of volatile organic compounds at the soil-litter interface. Biogeochemistry, 99, 97-107. https://doi.org/10.1007/s10533009-9393-x.

Reeve, H.K. (1989) The evolution of conspecific acceptance thresholds. The American Naturalist, 133, 407-435. https://doi.org/10.1086/ 284926 .
Rostás, M., Ruf, D., Zabka, V. \& Hildebrandt, U. (2008) Plant surface wax affects parasitoid's response to host footprints. Naturwissenschaften, 95, 997-1002. https://doi.org/10.1007/s00114008-0411-y.

Roth, H. \& Menzel, R. (1972) ERG of Formica polyctena and selective adaptation. Information Processing in the Visual Systems of Anthropods (ed. by R. Wehner), pp. 177-181. Springer, Berlin, Heidelberg. https://doi.org/10.1007/978-3-642-65477-0_26.

Roulston, T.H., Buczkowski, G. \& Silverman, J. (2003) Nestmate discrimination in ants: effect of bioassay on aggressive behavior. Insectes Sociaux, 50, 151-159. https://doi.org/10.1007/s00040-0030624-1.

Sagata, K. \& Lester, P.J. (2009) Behavioural plasticity associated with propagule size, resources, and the invasion success of the argentine ant Linepithema humile. Journal of Applied Ecology, 46, 19-27. https:// doi.org/10.1111/j.1365-2664.2008.01523.x.

Schröder, R. \& Hilker, M. (2008) The relevance of background odor in resource location by insects: a behavioral approach. Bioscience, $\mathbf{5 8}$, 308-316. https://doi.org/10.1641/B580406.

Seifert, B. (2007) Die Ameisen Mittel- und Nordeuropas. Lutra Verlagsund Vertriebsgesellschaft, Görlitz.

Singmann, H., Bolker, B., Westfall, J., Aust, F. \& Ben-Shachar M.S. (2020) Afex: Analysis of Factorial Experiments. R Package Version 0.28-0. https://CRAN.R-project.org/package=afex.

Sprenger, P.P. \& Menzel, F. (2020) Cuticular hydrocarbons in ants (Hymenoptera: Formicidae) and other insects: how and why they differ among individuals, colonies, and species. Myrmecological News, 30, 1-26.

Stapley, L. (1998) The interaction of thorns and symbiotic ants as an effective defence mechanism of swollen-thorn acacias. Oecologia, 115, 401-405. https://doi.org/10.1007/s004420050534.

Starks, P.T., Fischer, D.J., Watson, R.E. et al. (1998) Context-dependent nestmate discrimination in the paper wasp, polistes dominulus: a critical test of the optimal acceptance threshold model. Animal Behaviour, 56, 449-458. https://doi.org/10.1006/anbe.1998.0778.

Stevens, M. \& Merilaita, S. (2011) Animal Camouflage: Mechanisms and Function. Cambridge University Press, Cambridge, UK.

Stockan, J.A. \& Robinson, E.J.H. (2016) Wood Ant Ecology and Conservation. Cambridge University Press, Cambridge, UK.

Tanner, C.J. (2006) Numerical assessment affects aggression and competitive ability: a team-fighting strategy for the ant Formica xerophila. Proceedings of the Royal Society B: Biological Sciences, 273, 2737-2742. https://doi.org/10.1098/rspb.2006.3626.

Tartally, A., Thomas, J.A., Anton, C., Balletto, E., Barbero, F., Bonelli, S. et al. (2019) Patterns of host use by brood parasitic Maculinea butterflies across Europe. Philosophical Transactions of the Royal Society B, 374, 20180202.

Toffin, E., Kindekens, J. \& Deneubourg, J.L. (2010) Excavated substrate modulates growth instability during nest building in ants. Proceedings of the Royal Society B: Biological Sciences, 277, 2617-2625. https:// doi.org/10.1098/rspb.2010.0176.

Vander Meer, R.K. \& Wojcik, D.P. (1982) Chemical mimicry in the myrmecophilous beetle Myrmecaphodius excavaticollis. Science, 218, 806-808.

Wagner, D., Brown, M.J.F. \& Gordon, D.M. (1997) Harvester ant nests, soil biota and soil chemistry. Oecologia, 112, 232-236.

Ward, A.J.W., Duff, A.J., Horsfall, J.S. \& Currie, S. (2008) Scents and scents-ability: pollution disrupts chemical social recognition and shoaling in fish. Proceedings of the Royal Society B: Biological Sciences, 275, 101-105. https://doi.org/10.1098/rspb .2007.1283.

Wilson, J.K., Kessler, A. \& Woods, H.A. (2015) Noisy communication via airborne infochemicals. Bioscience, 65, 667-677. https://doi.org/ 10.1093/biosci/biv062. 
Wüst, M. \& Menzel, F. (2017) I smell where you walked-how chemical cues influence movement decisions in ants. Oikos, 126, 149-160. https://doi.org/10.1111/oik.03332.

van Zweden, J.S. \& d'Ettorre, P. (2010) Nestmate recognition in social insects and the role of hydrocarbons. Insect Hydrocarbons Biology, Biochemistry and Chemical Ecology (ed. by G. J. Blomquist and A.-G. Bagnères), pp. 222-243. Cambridge University Press, Cambridge.

Accepted 14 June 2021

First published online 23 July 2021

Associate Editor: Inge Armbrecht 